\title{
Targeted self-regulation interventions in low-income children: Clinical trial results and implications for health behavior change
}

\author{
Sharon L. Lo ${ }^{\mathrm{a}, \mathrm{b}, *}$, Ashley N. Gearhardt ${ }^{\mathrm{c}}$, Emily M. Fredericks ${ }^{\mathrm{d}}$, Benjamin Katz ${ }^{\mathrm{e}}$, \\ Julie Sturza $^{\mathrm{b}}$, Niko Kaciroti ${ }^{\mathrm{b}}$, Richard Gonzalez ${ }^{\mathrm{c}}$, Christine M. Hunter ${ }^{\mathrm{f}}$, \\ Kendrin Sonneville $^{\mathrm{b}}$, Kiren Chaudhry ${ }^{\mathrm{b}}$, Julie C. Lumeng ${ }^{\mathrm{b}, \mathrm{d}}$, Alison L. Miller ${ }^{\mathrm{b}}$ \\ ${ }^{a}$ School of Graduate Psychology, Pacific University, Hillsboro, OR 97123, USA \\ ${ }^{\mathrm{b}}$ School of Public Health, University of Michigan, Ann Arbor, MI 48109, USA \\ ${ }^{\mathrm{c}}$ Department of Psychology, University of Michigan, Ann Arbor, MI 48109, USA \\ ${ }^{\mathrm{d}}$ Department of Pediatrics, University of Michigan, Ann Arbor, MI 48109, USA \\ ${ }^{\mathrm{e}}$ Department of Human Development and Family Science, Virginia Tech, Blacksburg, VA 24061, USA \\ ${ }^{\mathrm{f}}$ Office of Behavioral and Social Sciences Research, National Institutes of Health, Bethesda, MD 20892, USA
}

\section{A R T I C L E I N F O}

\section{Article history:}

Received 13 November 2019

Revised 2 February 2021

Available online 25 April 2021

\section{Keywords:}

Self-regulation

Health behavior

Intervention

Executive function

Emotion regulation

Future orientation

\begin{abstract}
A B S T R A C T
Self-regulation, known as the ability to harness cognitive, emotional, and motivational resources to achieve goals, is hypothesized to contribute to health behaviors across the lifespan. Enhancing self-regulation early in life may increase positive health outcomes. During pre-adolescence, children assume increased autonomy in health behaviors (e.g., eating; physical activity), many of which involve self-regulation. This article presents results from a clinical trial (NCT03060863) that used a factorial design to test behavioral interventions designed to enhance self-regulation, specifically targeting executive functioning, emotion regulation, future-oriented thinking, and approach biases. Participants were 118 children (912 years of age, $M=10.2$ years) who had a history of living in poverty. They were randomized to receive up to four interventions that were delivered via home visits. Self-regulation was assayed using behavioral tasks, observations, interviews, and parent- and childreport surveys. Results were that self-regulation targets were reliably assessed and that interventions were delivered with high fidelity. Intervention effect sizes were very small to moderate $(d$ range $=.02-.65$, median $=.14$ ), and most were not statistically
\end{abstract}

* Corresponding author at: School of Graduate Psychology, Pacific University, Hillsboro, OR 97123, USA.

E-mail address: sharon.lo@pacificu.edu (S.L. Lo). 
significant. Intercorrelation analyses indicated that associations between measures within each target varied based on the selfregulation target evaluated. Results are discussed with regard to the role of self-regulation-focused interventions in child health promotion. Implications of findings are reviewed for informing next steps in behavioral self-regulation interventions among children from low-income backgrounds.

(c) 2021 Elsevier Inc. All rights reserved.

\section{Introduction}

Self-regulation is the capacity to manage thoughts, feelings, and behaviors in service of a goal (Blair \& Diamond, 2008; Mischel, Shoda, \& Rodriguez, 1989). Poor self-regulation skills during adulthood are linked to detrimental mental and physical health outcomes that require ongoing management and/or lifestyle changes (Bickel, Quisenberry, Moody, \& Wilson, 2015; Reimann et al., 2020). Identifying malleable self-regulation targets could yield sustained health behavior changes over time even if effects on self-regulation are small (O'Carroll, 2020). The Science of Behavior Change experimental medicine approach (Nielsen et al., 2018) focuses on measuring and engaging behavioral targets, such as selfregulation, that underlie larger health behavior changes.

The experimental medicine approach specifies the following steps. First, identify and reliably measure behavior change targets. Second, attempt to change ("engage") these targets using experimental manipulations. Third, validate whether such changes map on to health behaviors. The goal of this study was to apply the Science of Behavior Change approach to measure and attempt to engage four identified self-regulation targets in youths that have implications for health behaviors (Miller et al., 2018), specifically executive functioning, emotion regulation, future orientation, and approach bias. Middle childhood, specifically 9 to 12 years of age, was the developmental period of interest because this is a time of growth in independent self-regulation capacity and also advances in cognitive, emotional, and social skills relevant to development of healthy behaviors (DelGiudice, 2018). We use the term "youth" to describe children aged 9 to 12 years. The sample consisted of youths from low-income backgrounds, who are at risk for both poorer self-regulation and health outcomes compared with higher-income peers yet often are underrepresented in basic developmental science research (Raver, Blair, \& Willoughby, 2013). The current study comes at an important juncture in the field given calls to ensure inclusion of populations from impoverished and marginalized backgrounds, particularly regarding mechanisms for child health promotion (Brown, Mistry, \& Yip, 2019).

\section{Self-regulation in youths as a behavior change target}

Self-regulation emerges across development and is suggested to have transdiagnostic implications (Nigg, 2017; Robson, Allen, \& Howard, 2020). From a developmental trajectory perspective, enhancing self-regulation early in life may benefit multiple health outcomes. Determining feasibility of changing relevant self-regulation targets in youths is a critical first step prior to evaluating whether selfregulation interventions are promising for promoting health, yet this has not been systematically tested. Executive functioning, emotion regulation, future orientation and approach bias are selfregulation targets that have been shown to associate with a range of health behaviors and chronic conditions, as detailed below.

\section{Executive functioning}

Executive functions refer to top-down cognitive processes that are responsible for the selfregulation of thoughts and behaviors that support our ability to organize and direct goal-oriented behavior (Diamond, 2013; Nigg, 2017; Patrick, Blair, \& Maggs, 2008). Individual differences in execu- 
tive functions are implicated in several health behaviors (Reimann et al., 2020). Executive function difficulties may make it difficult not only to recall specific recommendations in the moment but also to plan ahead and execute health behaviors while managing competing demands. Moreover, although executive function is a proximal pathway to behavior, social norms and values about health can be shaped by environmental context, which may influence motivational factors relevant for executive functioning (Doebel, 2020).

Research has identified links between executive functions and health behaviors, although direction of association remains unclear (Allan, McMinn, \& Daly, 2016; Best, 2010; Blair, Kuzawa, \& Willoughby, 2020). Difficulties in shifting attention, managing impulses, and executing working memory skills associate with obesogenic eating (Groppe \& Elsner, 2014, 2015) and unhealthy diets (Riggs, SpruijtMetz, Chou, \& Pentz, 2011), precursors to pediatric health conditions such as obesity (Jansen, Houben, \& Roefs, 2015; Liang, Matheson, Kaye, \& Boutelle, 2014). Limited executive functioning skills are linked to medical regimen management challenges and poorer health outcomes among youths with chronic illness (Berg et al., 2014; Hall \& Marteau, 2014; Vloemans et al., 2019). Associations may result from poor adherence given that executive functions are critical for remembering regimen details (e.g., when to take medication), self-monitoring (e.g., checking blood glucose), and problem solving and planning (e.g., preparing pill box) around prescribed adherence goals (Lansing \& Berg, 2014). Alternatively, engaging in health-promoting behaviors such as aerobic exercise and mindfulness may enhance executive functions (Diamond \& Ling, 2019; Sun, Li, Cai, \& Wang, 2021).

Researchers have sought to enhance executive functioning in the context of health behaviors. For example, executive functioning training in youths with obesity led to improved working memory and healthy weight maintenance (Verbeken, Braet, Goossens, \& van der Oord, 2013). Executive functioning training has also yielded benefits in youths (Jaeggi, Buschkuehl, Jonides, \& Shah, 2011; Katz, Jaeggi, Buschkuehl, Stegman, \& Shah, 2014; Khalili Kermani, Mohammadi, Yadegari, Haresabadi, \& Sadeghi, 2016; Wass, 2014), including reduced impulsivity (Jones, Katz, Buschkuehl, Jaeggi, \& Shah, 2020). Despite promising results, there remains debate regarding the extent to which training effects transfer to real-world applications such as health behaviors and school functioning (e.g., Kassai, Futo, Demetrovics, \& Takacs, 2019; Luis-Ruiz et al., 2020). Researchers have posited that inconsistencies in "far transfer" effects may reflect the notion that cognitive training may be insufficient without the addition of skills that support broader strategy development (Katz, Shah, \& Meyer, 2018). We selected a commonly used specific executive functioning training approach (e.g., working memory training) that had been used in prior work, with the long-term goal to understand how this approach may perform within a multicomponent intervention.

\section{Emotion regulation}

Emotion regulation is the ability to modulate the valence and intensity of emotions in service of a goal. Pre-adolescence marks a time of heightened emotional reactivity and intensity as well as increased capacities to regulate thoughts, feelings, and behaviors. Poorer emotional awareness has been linked to poorer adherence among youths with chronic health conditions (Lansing \& Berg, 2014). Complex interactions among stress, emotions, and biology may affect health-related behaviors through maladaptive emotion regulation pathways that can become habits across development, for example, when strategies such as emotional eating, substance use, and risky behaviors serve to suppress and regulate negative emotions. Indeed, emotion regulation has been implicated in the development and maintenance of obesity through behavioral mechanisms that drive emotional overeating in response to stress (Levitan \& Davis, 2010; Turton, Chami, \& Treasure, 2017) and depressed mood (Isasi, Ostrovsky, \& Wills, 2013). Overreliance on such strategies is linked to later medical and mental health conditions, including addiction and substance abuse, eating disorders, and impulse control disorders (Weiss, Sullivan, \& Tull, 2015).

In contrast, youths who have well-developed emotion regulation skills tend to exhibit better behavioral and social functioning, physiological regulation, and physical health (Calkins, Dollar, \& Wideman, 2019). Interventions targeting emotion regulation have improved impulse control, reduced problem behaviors, and increased academic functioning (Wyman et al., 2010). Small studies with pediatric populations suggest that targeted interventions may improve child emotion regulation 
capacity (Shockey et al., 2013). The current study used biofeedback and relaxation activities, both of which have been shown to enhance emotion regulation (Lehrer et al., 2020).

\section{Future orientation}

Future-oriented thinking is the process of visualizing and valuing future events and is a selfregulation target that may enhance youths' capacity to "mentally project" and invest in their future health (Miller \& Brickman, 2004; Nurmi, 2005). The episodic and relational memory skills needed to recall past details and inform future goals accelerate rapidly during middle childhood (Gott \& Lah, 2014; Prabhakar \& Hudson, 2014). Therefore, middle childhood is an ideal period to promote future-oriented thinking. Episodic future thinking (EFT) interventions, which encourage individuals to practice "bringing the future to the present," can alter delay discounting, or the preference for smaller immediate rewards versus larger delayed rewards, which has many health behavior implications (Stein et al., 2016). Among 9- to 14-year-olds, EFT interventions were shown to reduce delay discounting and energy intake (Daniel, Said, Stanton, \& Epstein, 2015; Lin \& Epstein, 2014). Given the importance of the ability to make healthy choices in the moment to satisfy future needs, the study of future thinking has garnered much attention. Yet, future orientation is rarely considered as a target for health behavior change in youths. In the current study, we used EFT approaches to promote child future orientation.

\section{Approach bias}

Finally, cues consistently paired with substances or food become powerful conditioned stimuli that can trigger substance use or food consumption despite motivations not to do so (Berridge, Ho, Richard, \& DiFeliceantonio, 2010). The tendency to approach rather than avoid such cues is known as approach bias. Approach bias is associated with a drive for substances like alcohol and cigarettes (R. W. Wiers et al., 2007) and food (Dickson, Kavanagh, \& MacLeod, 2016), which could increase the self-regulation needed to modulate intake. Thus, approach biases may be an important self-regulation target with health implications. This has rarely been considered in youths. Research suggests that approach biases may be modified by training individuals to push a joystick away to avoid conditioned cues and to pull the joystick closer to approach other stimuli (Eberl et al., 2013). Engaging in such approach-avoidance training has been shown to reduce substance use (Eberl et al., 2013; C. E. Wiers et al., 2015) and is implicated in changing food-specific approach bias (Houben \& Jansen, 2015; Kakoschke, Kemps, \& Tiggemann, 2017). Altering approach bias early in development may be important in shaping later health behavior (Lau, 2013). We created an approach-avoidance training task to reduce approach bias in youths.

\section{The current study}

This study examined executive functioning, emotion regulation, future orientation, and approach bias as health-related self-regulation targets in youths. Goals were to use multimethod assessments and manipulate these targets using the interventions described below and assess the extent to which interventions enhanced self-regulation. Given recent reviews highlighting discrepancies between task- and questionnaire-based measures (Doebel, 2020; Eisenberg et al., 2019), we assessed outcomes with both task-based and questionnaire-based measures when possible. Intercorrelations across measures within each self-regulation target were evaluated. Additional goals were to assess the feasibility and fidelity of delivering self-regulation interventions in a home setting with youths from low-income households. Hypotheses were that youths who received an intervention addressing a given selfregulation target would exhibit better outcomes for that target compared with youths who did not receive that intervention.

\section{Method}

Participants

Participants were drawn from a cohort of youths $(N=256 ; 56 \%$ White/non-Latinx; $49 \%$ male) (Miller et al., 2018) who were initially enrolled when they were preschool aged (3-5 years) and attending Head Start preschools, which serve families in poverty. The University of Michigan institu- 
tional review board approved the protocol. Parents completed informed consent, and youths provided assent. Current study data were gathered when youths were 9 to 12 years old. This study was described as "learning about how participating in different activities may affect child attention, emotions, and behavior"; the CONSORT diagram presents recruitment and enrollment numbers. Of the 118 youths who were randomized and completed pretest assessments, 13 did not complete posttest assessments, leaving 105 for analysis (see Fig. 1).

\section{Study design}

The study was preregistered on ClinicalTrials.gov (NCT03060863). We used a factorial design to maximize power to test intervention effects on specific self-regulation targets (Collins, Dziak, Kugler, \& Trail, 2014). A random number generator was used to randomize participants to conditions in which they received 0 to 4 of the interventions. When youths were assigned to more than one condition, the generator assigned the order in which they would receive each intervention. Intervention fidelity and dose were assessed. Self-regulation was assessed at pre- and post-intervention.

\section{Self-regulation interventions}

Interventions were designed to be developmentally appropriate for youths in our age range. Interventions were manualized and delivered during three home visits over a 6 -week period by a trained bachelor's-level interventionist. Sessions were coded for fidelity from video. All outcomes were assessed at pre-intervention and 6 weeks post-intervention by trained examiners blind to intervention condition. Questionnaires and tasks were individually administered; items on child-reported surveys were read aloud by examiners. Measurement details are reported elsewhere (Miller et al., 2018) and reviewed below. Reliability statistics for study measures are provided in Table 1.

\section{Executive function}

The executive functioning intervention used a tablet-based game designed to improve working memory that demonstrated transfer effects to other executive function components (Jaeggi et al., 2011; Katz et al., 2014). The interventionist taught the child how to play the "N-back" game, which displayed sequential images (e.g., fruit, animals) and prompted the child to tap the screen when an image matched a previous image. The game became more challenging as the child showed competency, requiring matches of three, four, or more images "back." The game was played for 10 rounds. Because it is most effective to practice daily across a few weeks (Wang, Zhou, \& Shah, 2014), tablets were left with the family for practice between visits. Youths were instructed to play 10 rounds once per day. At the first visit, parent-child dyads generated a schedule for home practice. At subsequent visits, the child and interventionist reviewed the plan, adjusted as needed, and played 10 rounds of the game. At the end of each visit, the child selected a prize based on cumulative score. Families also received text message practice reminders.

\section{Emotion regulation}

The emotion regulation intervention used biofeedback and guided relaxation techniques. A computer-based program, Journey to the Wild Divine (Bell, 2003; Divine, 2006), was used to show the child how to use breathing techniques to change skin conductance and heart rate variability. These physiological indices were recorded using finger sensors, graphing the data in real time. The interventionist showed the child how to alter the graph's status bars by moving and breathing (e.g., wiggling fingers, taking slow breaths), saying "this colored bar is showing us how calm your body is." The interventionist then guided the child in a diaphragmatic breathing activity, instructing the child to match his or her pace of breathing to a graphic of butterfly wings that opened and closed. The child then used deep breathing to steer balloons across the screen. Lastly, the child was guided in a progressive muscle relaxation activity. As with executive functioning, a home practice plan was developed, and the interventionist left laminated instruction cards to practice at least one of the breathing techniques each day. 


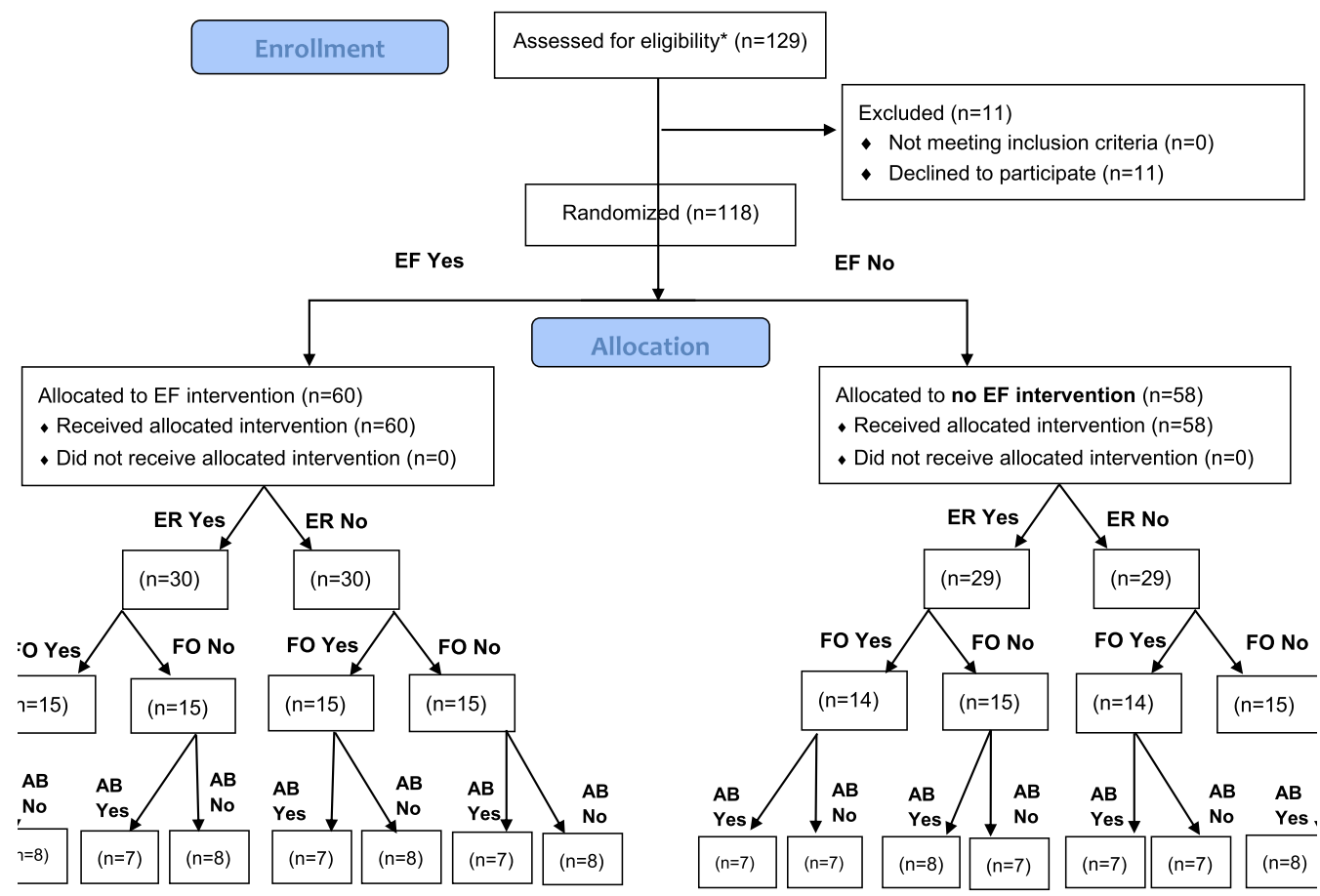

Follow-Up

Jw-up / discontinued (family declined to participate)

\begin{tabular}{l|l|l|}
\hline$(n=2)$ & $(n=0)$ & $(n=2)$ \\
\hline
\end{tabular}

\begin{tabular}{|l|l|l|l|}
\hline$(n=2)$ & $(n=1)$ & $(n=1)$ & $(n=0)$ \\
\hline
\end{tabular}

\begin{tabular}{||l||l||l|l|}
\hline$(n=1)$ & $(n=1)$ & $(n=0)$ & $(n=1)$ \\
\hline
\end{tabular}

\begin{tabular}{|l||l||l|}
\hline$(n=1)$ & $(n=0)$ & $(n=0)$ \\
\hline
\end{tabular}

\section{Analysis}

te: no participants were excluded from analysis; $N=105$ )

\begin{tabular}{l||l|l|}
\hline$(n=6)$ & $(n=7)$ & $(n=6)$ \\
\hline
\end{tabular}

\begin{tabular}{|l||l|l|l|}
\hline$(n=5)$ & $(n=7)$ & $(n=6)$ & $(n=8)$ \\
\hline
\end{tabular}

\begin{tabular}{|c|c|c|c|}
\hline$(n=6)$ & $(n=6)$ & $(n=8)$ & $(n=6)$ \\
\hline
\end{tabular}

\begin{tabular}{l|l|l}
\hline$(n=6)$ & $(n=7)$ & $(n=8)$ \\
\hline
\end{tabular}

Fig. 1. CONSORT flow diagram. A total of 380 children participated in the original study at 3 to 5 years of age. We retained contact with 256 families at 9 to 12 years of age when this study was conducted. Of those, 129 were randomized. Of the 118 children who were randomized and completed pretest assessments, 13 did not complete posttest assessments, leaving 105 for analysis. EF, executive functioning intervention ( $N$-back); ER, emotion regulation intervention (relaxing rhythms); FO, future orientation intervention (episodic future thinking); $\mathrm{AB}$, approach bias intervention.

\section{Future orientation}

The future orientation intervention was based on prior work in young adolescents (Oyserman, Brickman, \& Rhodes, 2007) showing that visualizing and writing about future events may enhance 
Table 1

Demographics and descriptive sample characteristics.

\begin{tabular}{|c|c|c|c|c|}
\hline Demographic variable & $n$ & & $\%$ & \\
\hline Female & 58 & & 55 & \\
\hline \multicolumn{5}{|l|}{ Child ethnicity } \\
\hline White non-Latinx & 60 & & 57 & \\
\hline White Latinx & 6 & & 5.7 & \\
\hline Black non-Latinx & 16 & & 15 & \\
\hline Multiracial non-Latinx & 16 & & 15 & \\
\hline Multiracial Latinx & 4 & & 3.8 & \\
\hline Latinx, race not specified & 3 & & 2.9 & \\
\hline \multicolumn{5}{|l|}{ Maternal education } \\
\hline High school or less & 47 & & 45 & \\
\hline Some college & 34 & & 32 & \\
\hline 2 -year college & 13 & & 12 & \\
\hline \multirow[t]{2}{*}{ 4-year college of above } & 10 & & 10 & \\
\hline & $M$ & & $S D$ & \\
\hline Age (in months) & 128.9 & & 6.4 & \\
\hline Income-to-needs ratio & 1.4 & & 0.9 & \\
\hline Home chaos & 3.9 & & 3.1 & \\
\hline Maternal CES-D total & 12.4 & & 10.5 & \\
\hline Maternal ACE score & 3.5 & & 2.9 & \\
\hline Self-regulation target & Pre $\alpha$ & Post $\alpha$ & Pretest $M$ & Pretest $S D$ \\
\hline \multicolumn{5}{|l|}{ Executive functioning } \\
\hline Forward digit span & NA & NA & 7.3 & 2.2 \\
\hline Backward digit span & NA & NA & 6.9 & 1.8 \\
\hline Go/no-go task, total accuracy & NA & NA & 0.9 & 0.1 \\
\hline Go/no-go task, false alarms & NA & NA & 7.2 & 10.5 \\
\hline Go/no-go task, reaction time & NA & NA & 564.0 & 71.3 \\
\hline \multicolumn{5}{|l|}{ Emotion regulation } \\
\hline Child-report affect regulation (SIDES) & 0.69 & 0.69 & 1.9 & 0.6 \\
\hline Child-report CEMS Anger Dysregulation & 0.61 & 0.61 & 1.7 & 0.5 \\
\hline Child-report CEMS Anger Coping & 0.68 & 0.69 & 2.2 & 0.5 \\
\hline Child-report CEMS Worry Dysregulation & 0.58 & 0.67 & 1.6 & 0.5 \\
\hline Child-report CEMS Worry Coping & 0.57 & 0.22 & 2.0 & 0.6 \\
\hline Observed frustration in backward math & NA & NA & .3 & 0.2 \\
\hline Parent-reported NIH Perceived Stress & 0.88 & 0.88 & 2.4 & 0.6 \\
\hline Parent-reported PANAS, positive affect & 0.91 & 0.92 & 3.5 & 0.8 \\
\hline Parent-reported PANAS, negative affect & 0.86 & 0.84 & 1.9 & 0.7 \\
\hline \multicolumn{5}{|l|}{ Future orientation } \\
\hline Child-report NIH Self-Efficacy & 0.85 & 0.82 & 3.4 & 0.8 \\
\hline Child-report future time perspective & 0.67 & 0.69 & 3.0 & 0.8 \\
\hline Child-report delay choice & NA & NA & 4.4 & 3.1 \\
\hline Future events, proportion internal words & NA & NA & 51.1 & 32.5 \\
\hline Future events, proportion external words & NA & NA & 24.5 & 39.7 \\
\hline \multicolumn{5}{|l|}{ Approach bias } \\
\hline IAT D-score & NA & NA & 0.1 & 0.3 \\
\hline Fixed ratio completed RRV candy & NA & NA & 1019 & 982 \\
\hline Child-report Power of Food Scale & 0.93 & 0.90 & 1.0 & 0.9 \\
\hline
\end{tabular}

Note. All behavioral tasks were completed by the child. These included the following: digit span, go/no-go task, observed frustration in backward math, future events interview, IAT, fixed ratio completed RRV candy. CES-D, Center for Epidemiologic Studies Depression Scale; ACE, Adverse Childhood Events; SIDES, Structured Interview for Disorders of Extreme Distress; CEMS, Child Emotion Management Scales; NIH, National Institutes of Health; PANAS, Positive Affect and Negative Affect Schedule; IAT, Implicit Association Test; RRV, relative reinforcing value.

future orientation and research using EFT methods with pre-adolescents (Daniel et al., 2015). At each visit, the interventionist asked the child to describe three upcoming positive events while using as many details as possible. The child was prompted with time cues (e.g., "next week," "a few months") and was asked to describe events using concrete details (e.g., who will be there, where the event will take place, visual/sensory information) in order to make the experience as vivid as possible. There were no home practice activities because the intervention was administered in person. 


\section{Approach bias}

Modeled after experimental studies with adults (Dickson et al., 2016), the approach bias intervention was a timed game in which the child categorized food images as healthy or unhealthy. First, the child completed a card sort, dividing pictures of eight common foods into healthy (e.g., carrots) and unhealthy (e.g., cupcake) piles. The interventionist corrected discrepancies by explaining that healthy food "is healthy because it helps our bodies do the work they need to" and that unhealthy food "is not so good for our bodies." Next, the child used a joystick to pull healthy foods forward and push unhealthy foods away on a computer screen. When pulled toward the child, the image grew larger to fill the screen; when pushed away, the image disappeared into the horizon. At each visit, the child played the game twice, sorting 40 foods each time, and tried to beat the prior score. This intervention had no home practice because the game was administered on a laptop.

\section{Control}

Families assigned to "no intervention" received three phone calls in order to maintain contact. Parents reported on child bedtimes and completed a 3-item survey about child behavior (Sleddens, Kremers, De Vries, \& Thijs, 2013).

\section{Measures}

\section{Self-regulation target outcomes}

For additional details regarding the measures that were developed or adapted for this study, refer to Miller et al. (2018).

\section{Executive functioning}

Executive functioning outcomes included working memory and inhibitory control. Working memory was assessed using forward and backward digit span tasks. More digits correctly repeated indicated better working memory (Wechsler, 2003). Inhibitory control was assessed using a go/no-go task (Grammer, Carrasco, Gehring, \& Morrison, 2014). The child was asked to press a key as quickly as possible when presented with a "go" stimulus and to inhibit this response when presented with a "no-go" stimulus. Scoring was based on accuracy and reaction time; faster and more accurate responses indexed better inhibitory control (Akshoomoff et al., 2013; Grammer et al., 2014).

\section{Emotion regulation}

Emotion regulation was assessed using observations, child self-report, and parent report. The child completed three 1-min backward math tasks adapted from prior work (Buske-Kirschbaum et al., 1997). Tasks became progressively more difficult (count backward by $5 \mathrm{~s}$ from 400, by $3 \mathrm{~s}$ from 501, and by $7 \mathrm{~s}$ from 758). Indicators of frustration (e.g., scowl, worried face, crying) were coded reliably from video (criterion: Cohen's kappa >.70 or intraclass correlation coefficient [ICC] > .80) as present or absent in 5-s intervals based on prior work (Berger, Miller, Seifer, Cares, \& LeBourgeois, 2012). Proportion of time displaying frustration indicated poorer emotion regulation. The child completed a 6item scale based on the Structured Interview for Disorders of Extreme Distress (SIDES; Brown et al., 2012) to assess frequency of disruptive emotions (e.g., "Small problems got me very upset"; higher scores indicated poorer emotion regulation) and the 21-item Children's Emotion Management Scales (CEMS) to assess strategies for managing anger and worry (e.g., "When I am feeling mad, I can stop myself from losing my temper"). Higher coping and lower dysregulation scores reflected more effective emotion regulation (Zeman, Shipman, \& Penza-Clyve, 2001). Parents reported on child emotion regulation using the 10-item National Institutes of Health (NIH) Perceived Stress Scale (PSS; Kupst et al., 2015) and the 20-item Positive and Negative Affect Schedule (PANAS) for youths (Ebesutani, Okamura, Higa-McMillan, \& Chorpita, 2011). The PSS is scored such that higher scores indicate poorer emotion regulation (greater stress); the PANAS is scored such that higher scores indicate better emotion regulation (more positive vs. negative emotions). 


\section{Future orientation}

Future orientation was assessed using a semistructured interview and self-report questionnaires. The interview was based on prior work with youths from low-income backgrounds (McCabe \& Barnett, 2000) and autobiographical memory studies in youths (Addis, Wong, \& Schacter, 2008; Bromberg, Wiehler, \& Peters, 2015; Gott \& Lah, 2014). The interviewer asked the child to describe three different events in the future that the child was looking forward to. The interviewer guided the child through imagining the event using prompts such as "Try to describe it in a way where I am able to imagine what it will be like for you" and additional prompts to facilitate details such as "What will be happening around you?"; "Tell me who you'll be with"; "How will you be feeling"; and "What do you see?" Child responses were coded (Cohen's kappa > .70) from audiotape using systems adapted from prior work (Addis et al., 2008; Bromberg et al., 2015). Indicators of future orientation included use of detail, vivid imagery, and "episodic" language reflecting experiential details that are internal, versus external or extraneous, to an anticipated event. The proportion of internal and external words used to describe future events out of total utterances was calculated to indicate future orientation (more internal words indicated greater future orientation). The child completed the 10item NIH Self-Efficacy questionnaire (Kupst et al., 2015), which assessed capacity for control over life events, and the 13-item Future Orientation scale (Zimbardo \& Boyd, 2015), where some items were adapted to be child appropriate (Barnett et al., 2013; Wills, Sandy, \& Yaeger, 2001) (e.g., changing "It upsets me to be late for appointments" to "It upsets me to be late for school"). Higher scores indicated greater future orientation. The child also responded to 9 questions (Koffarnus \& Bickel, 2014) regarding whether he or she would rather have a smaller amount of a desired food sooner or a larger amount later. Delay choice preference was calculated as the ratio of preferences for immediate rewards over delayed rewards (higher values indicated less future orientation).

\section{Approach bias}

Approach bias was measured with tasks and questionnaires designed to assess bias toward palatable foods. A relative reinforcing value (RRV) task was used to assess how much the child was willing to work to gain access to candy (Gearhardt et al., 2017; Raynor \& Epstein, 2003). The child played a computer shape-matching game to win candy, pressing a key until shapes matched and receiving 1 point when all shapes matched. Every 5 points, the child could exchange a ticket for candy. The reinforcement schedule began at 10 presses to earn 1 point, doubling each time a ticket was earned; more presses indicated greater motivation to work for candy (higher approach bias). Because approach bias is thought to be implicit, approach bias toward chocolate was measured using a task that assessed implicit associations between images of chocolate and "stopping" versus "going" (Miller et al., 2018). This single-category Implicit Association Test (IAT) was adapted based on methods used to measure adults' attitudes about chocolate and candy (Houben \& Jansen, 2015; Kemps, Tiggemann, Martin, \& Elliott, 2013). The child sorted "stop" versus "go" signals by pressing one button when a signal was paired with chocolate (e.g., "go + chocolate") and the other button for the other (unpaired) signal ("stop") for a total of 48 trials. Over the next 48 trials, the pattern was reversed; the child sorted "stop" versus "go" signals based on the alternate signal-chocolate pairing (e.g., "stop + chocolate" vs. "go"). The order was counterbalanced such that half of the youths sorted chocolate with "stop" and then with "go." Scores were calculated using the D600 scoring protocol (Greenwald, Nosek, \& Banaji, 2003) to obtain the IAT D-score; higher values indicated a stronger implicit association between chocolate and "go" (approach bias for chocolate). The child also completed the 15-item Power of Food Scale, a measure of responsiveness to environmental food cues (Cappelleri et al., 2009; Lowe et al., 2009). Higher scores reflected greater approach bias toward palatable foods.

\section{Covariates}

Mothers reported on demographics (child sex, race/ethnicity, maternal education, and income) and completed the Confusion, Hubbub, and Order Scale (CHAOS) scale, a 15-item scale with higher scores indicating more household chaos (Matheny, Wachs, Ludwig, \& Phillips, 1995), and the Center for Epidemiological Studies-Depression (CES-D) scale, a 20-item scale with higher scores indicating more frequent depression symptoms (Radloff, 1977). Family income-to-needs ratio (ITNR) was calculated by 
dividing household income by the federal poverty threshold for a family of that size (ITNR $<1.0$ indicates living below poverty threshold; ITNR $<2.0$ indicates low income (U.S. Bureau of the Census, 2018).

\section{Intervention fidelity and dosage}

Intervention fidelity was assessed based on $29 \%$ of intervention videos. Videos were independently and reliably coded (Cohen's kappa > .75 or ICC > .91) using 23 items assessing the extent to which the interventionist accurately delivered essential intervention components. Items were rated from 1 (did not meet expectations) to 3 (exceeded expectations). Dosage was measured using home practice logs for emotion regulation (parent report and child report of home practice) and executive functioning interventions (electronic downloads of home practice).

\section{Analysis plan}

First, we examined psychometrics of the self-regulation measures (criterion of Cronbach's $\alpha>.65$ indicated acceptable reliability; Vaske, Beaman, \& Sponarski, 2017) and intercorrelations among measures within each self-regulation target at pretest and posttest. Then, we performed a randomization check and assessed intervention fidelity and dosage. We tested the extent to which interventions engaged self-regulation targets using an intent-to-treat basis and a difference-in-differences approach (Dimick \& Ryan, 2014). Independent-samples $t$ tests were conducted to test whether each factor (intervention) had a significant effect on the change in each self-regulation target from pre-intervention to post-intervention (equivalent to tests of interactions). A self-regulation target was considered "engaged" if intervention participation changed that target. The study was powered to detect medium effect sizes (Cohen's $d=.53$ ). Effect sizes are reported as Cohen's $d$ with the following definitions (Sawilowsky, 2009): $d=.01$ (very small effect), $d=.20$ (small effect), $d=.50$ (medium effect), and $d=.80$ (large effect). Although the focus of the current study was to test specific impacts of interventions within target self-regulation domains, the factorial design allows for testing the possibility of cross-domain effects (Collins et al., 2014).

\section{Results}

\section{Psychometrics}

Results suggested that most youths' self-report measures showed moderate to strong internal consistency. Of the 11 measures for which Cronbach's $\alpha$ could be calculated, 8 measures had $\alpha$ s $>.67$ (see Table 1) at pretest and posttest. The CEMS was least reliable, with particularly low posttest reliability for Worry Coping. Parent-reported measures showed higher reliability.

\section{Intercorrelations among measures}

Bivariate correlations were conducted to assess associations among measures of each selfregulation target. The sample sizes for intercorrelations ranged from 89 to 118 depending on which pretest and posttest measures were completed by participants. Among executive functioning measures, forward and backward digit spans were positively correlated with go/no-go accuracy (pretest: $r=.24, p=.008$, and $r=.19, p=.04$, respectively; posttest: $r=.24, p=.01$, and $r=.21, p=.03$, respectively) and were negatively correlated with go/no-go reaction time (pretest: $r=-.18, p=.05$, and $r=-.20, p=.03$; posttest: $r=-.20, p=.04$, and $r=-.23, p=.02$ ) such that higher digit span scores were associated with higher accuracy and faster reaction times.

For emotion regulation, child-reported affect regulation difficulties on the SIDES were associated in expected directions with child-reported anger dysregulation, anger coping, and worry dysregulation at pretest $(r=.33, p<.001, r=-.20, p=.03$, and $r=.40, p<.001$, respectively). At posttest, associations were similar $(r=.57, p<.001, r=-.38, p<.001$, and $r=.40, p=.001)$, and child-reported affect regulation difficulties were associated with parent-reported perceived stress in the expected direction $(r=.34, p<.001)$. Although not significant at pretest, observed frustration in the backward math task at posttest was positively associated with child-reported SIDES $(r=.23, p=.02)$ and parent-reported perceived child stress $(r=.21, p=.04)$. At pretest, parent-reported PANAS negative affect was positively associated with parent-reported perceived child stress $(r=.40, p<.001)$. At posttest, parent- 
reported PANAS positive affect was negatively associated with child-reported SIDES $(r=-.20$, $p=.05$ ), and parent-reported PANAS negative affect was positively associated with child-reported worry dysregulation and parent-reported perceived child stress $(r=.26, p=.01$, and $r=.45, p<.001$, respectively). Lastly, parent-reported perceived child stress at pretest and posttest was associated with greater child-reported anger dysregulation and lower anger coping (pretest: $r=.36, p<.001$, and $r=-.28$. $p=.002$, respectively; posttest: $r=.26, p=.01$, and $r=-.20, p=.05$ ).

Among future orientation measures, child-reported self-efficacy was associated with better future orientation as reported on the future time perspective scale at pretest and posttest $(r=.50, p<.001$, and $r=.58, p<.001$, respectively). Preference for delayed rewards on the delay choice task was associated with higher child-reported self-efficacy at posttest $(r=-.24, p=.01)$, but not at pretest $(r=-.15, p=.10)$. Higher future time perspective scores were associated with preference for delayed rewards at posttest $(r=-.20, p=.04)$, but not at pretest $(r=-.12, p=.21)$.

Measures used to assess approach bias were unrelated at pretest and posttest, suggesting that the behavioral IAT, relative reinforcing task, and child-reported Power of Food Scale may measure distinct aspects of approach bias.

\section{Randomization, intervention fidelity, and dosage}

Our randomization check was conducted using $t$ tests to compare target intervention and nontarget intervention groups. Chi-square tests and $t$ tests indicated no difference between groups for child sex and race/ethnicity. There was no difference in child age with the exception of EFT, where those with the intervention were 130 months old $(S D=6.3)$ compared with those without the intervention who were 128 months old $(S D=6.3), p=.02$. The $t$ tests also indicated no differences in outcome variables between intervention groups at baseline.

Intervention fidelity was high, with interventionists meeting or exceeding expectations (mean score $=2.9 / 3.0$ for executive functioning, 2.8 for emotion regulation and approach bias, and 2.7 for future orientation). Percentage of intervention visits rated as "meeting or exceeding" expectations ranged from $97.2 \%$ (approach bias) to $99.7 \%$ (emotion regulation). Dosage for interventions with a home practice component (executive functioning and emotion regulation) was high. Because there was no home practice component for future orientation and approach bias, dosage was not assessed. Youths reported practicing emotion regulation intervention activities an average of 18 days $(S D=9$, range $=5-28$, goal $=25$ ). Electronic $N$-back records indicated that youths practiced an average of 143.4 out of 280 possible rounds $(S D=89.2)$ with a high level of accuracy $(M=88.5 \%)$.

\section{Intervention effects}

Table 2 presents intervention analysis results. Mean changes presented in the table are not adjusted for any potential effects of the other treatments. ${ }^{1}$ Given the small sample size, we note statistically significant findings $(\alpha=.05)$ and marginal findings $(\alpha=.10)$ in the table and comment only on effect sizes of $d=.20$ or above (reflecting a small effect size) in our presentation of results. For transparency, Bonferroni corrections are provided for effects that reached statistical significance $(\alpha=.05)$ or marginal significance $(\alpha=.10)$ to correct for multiple corrections (number of tests for executive functioning $=5$, number of tests for emotion regulation $=9$, number of tests for future orientation $=5$, number of tests for approach bias $=3$ ).

\section{Executive functioning}

Youths who participated in the executive functioning intervention did not exhibit significant differences in digit span or go/no-go outcomes.

\section{Emotion regulation}

Youths who participated in the emotion regulation intervention, compared with those who did not, reported significantly fewer instances of CEMS Anger Dysregulation $(d=-.65, p=.002$, Bonferroni-

\footnotetext{
${ }^{1}$ To address the unbalanced design, all analyses were also conducted using generalized linear models comparing targeted intervention versus control adjusting for other treatments. Results were nearly identical and therefore are not presented in the article, but they are available on request.
} 
Table 2

Descriptive statistics on changes in nontarget and target intervention groups by self-regulation target.

\begin{tabular}{|c|c|c|c|c|c|c|}
\hline & $\begin{array}{l}\text { Mean change in } \\
\text { nontarget group }\end{array}$ & $n$ & $\begin{array}{l}\text { Mean change in target } \\
\text { intervention }\end{array}$ & $n$ & $\begin{array}{l}\text { Effect } \\
\text { size }\end{array}$ & $\begin{array}{l}p \\
\text { Value }^{\mathrm{a}}\end{array}$ \\
\hline \multicolumn{7}{|l|}{ Executive functioning } \\
\hline Forward digit span & 0.53 & 53 & 0.67 & 52 & .08 & .68 \\
\hline Backward digit span & -0.21 & 52 & 0.12 & 51 & .19 & .35 \\
\hline Go/no-go task, total accuracy & 0.03 & 52 & 0.02 & 51 & -.10 & .60 \\
\hline Go/no-go task, false alarms & -1.83 & 52 & -0.24 & 51 & .16 & .42 \\
\hline Go/no-go task, reaction time & -25.59 & 52 & -31.22 & 51 & -.09 & .63 \\
\hline \multicolumn{7}{|l|}{ Emotion regulation } \\
\hline $\begin{array}{l}\text { Child-report affect regulation } \\
\text { (SIDES) }\end{array}$ & 0.15 & 49 & 0.16 & 51 & .03 & .90 \\
\hline $\begin{array}{l}\text { Child-report CEMS Anger } \\
\text { Dysregulation }\end{array}$ & 0.24 & 45 & -0.09 & 47 & $-.65^{* *}$ & .002 \\
\hline $\begin{array}{l}\text { Child-report CEMS Anger } \\
\text { Coping }\end{array}$ & -0.10 & 49 & -0.01 & 49 & .15 & .46 \\
\hline $\begin{array}{l}\text { Child-report CEMS Worry } \\
\text { Dysregulation }\end{array}$ & 0.01 & 47 & -0.07 & 49 & -.15 & .46 \\
\hline $\begin{array}{l}\text { Child-report CEMS Worry } \\
\text { Coping }\end{array}$ & 0.17 & 47 & 0.07 & 50 & -.14 & .51 \\
\hline $\begin{array}{l}\text { Observed frustration in } \\
\text { backward math }\end{array}$ & -0.01 & 51 & 0.00 & 51 & .05 & .81 \\
\hline $\begin{array}{l}\text { Parent-reported NIH Perceived } \\
\text { Stress }\end{array}$ & 0.01 & 48 & -0.16 & 47 & $-.37^{\dagger}$ & .07 \\
\hline $\begin{array}{l}\text { Parent-reported PANAS, } \\
\text { positive affect }\end{array}$ & -0.02 & 50 & 0.05 & 50 & .11 & .59 \\
\hline $\begin{array}{l}\text { Parent-reported PANAS, } \\
\text { negative affect }\end{array}$ & -0.05 & 50 & 0.00 & 50 & .10 & .61 \\
\hline \multicolumn{7}{|l|}{ Future orientation } \\
\hline Child-report NIH self-efficacy & 0.06 & 53 & 0.12 & 48 & .08 & .70 \\
\hline $\begin{array}{l}\text { Child-report future time } \\
\text { perspective }\end{array}$ & 0.32 & 52 & 0.16 & 48 & -.20 & .32 \\
\hline Child-report delay choice & -0.64 & 54 & -0.56 & 49 & .02 & .91 \\
\hline $\begin{array}{l}\text { Future events, proportion } \\
\text { internal words }\end{array}$ & -5.56 & 54 & 10.73 & 48 & $.45^{*}$ & .02 \\
\hline $\begin{array}{l}\text { Future events, proportion } \\
\text { external words }\end{array}$ & -0.56 & 54 & -7.27 & 48 & -.20 & .32 \\
\hline \multicolumn{7}{|l|}{ Approach bias } \\
\hline IAT D-score & -0.01 & 48 & 0.00 & 52 & .02 & .92 \\
\hline $\begin{array}{l}\text { Fixed ratio completed RRV } \\
\text { candy }\end{array}$ & -446.20 & 52 & -315.50 & 53 & .14 & .48 \\
\hline Power of Food Scale & 0.22 & 49 & 0.34 & 51 & .17 & .39 \\
\hline
\end{tabular}

Note. Mean changes presented in the table are not adjusted for any potential effects of other treatments. SIDES, Structured Interview for Disorders of Extreme Distress; CEMS, Child Emotion Management Scales; NIH, National Institutes of Health; PANAS, Positive Affect and Negative Affect Schedule; IAT, Implicit Association Test; RRV, relative reinforcing value.

${ }^{a} p$ Values are unadjusted, and Bonferroni corrections are presented in the text.

$\dagger p<.10$.

$p<.05$.

$p<.01$.

corrected $p=.02$ ). There was a trend-level reduction in parent-reported perceived stress among youths who participated in the emotion regulation intervention $(d=-.37, p=.07$, Bonferronicorrected $p=.63$ ).

\section{Future orientation}

Compared with youths in the non-future orientation groups, youths in the future orientation intervention group described significantly more episodic details related to future events in the interview 
$(d=.45, p=.02$, Bonferroni-corrected $p=.10)$, indicating an enhanced ability to bring to mind future events. Similarly, less extraneous or semantic information not specific to the future event were provided by youths in the intervention group, although this difference was not significant $(d=-.20$, $p=.32$ ). Youths in the future orientation intervention group also reported valuing present events more than future events on the Future Time Perspective scale $(d=-.20, p=.32)$, suggesting that they might not engage in behaviors that prioritize long-term gains, although group differences were not significant.

\section{Approach bias}

No effect of approach bias intervention was observed on measures of this self-regulation target $(.02<d<.17)$.

\section{Post hoc analyses: Cross-domain effects}

We used the same methods to test cross-domain effects (e.g., effect of executive functioning intervention on emotion regulation, future orientation, and approach bias targets) as for testing main intervention effects (e.g., effect of executive functioning intervention on executive functioning target). With Bonferroni corrections, results indicated that the executive functioning intervention had a significant effect on IAT D-score such that youths who received the executive functioning intervention exhibited a higher D-score, reflecting a stronger approach bias toward chocolate $(d=.53, p=.01$, Bonferroni-corrected $p=.03$ ). A significant difference was observed for the go/no-go accuracy rate between youths who received the emotion regulation intervention and those who did not such that those who did not receive it exhibited greater improvements in accuracy $(d=-.65, p=.002$, Bonferroni-corrected $p=.01$ ). All other intervention effects either were null or did not survive Bonferroni correction.

\section{Discussion}

Self-regulation skills during childhood are implicated across multiple adult outcomes, including health behaviors. To our knowledge, the current investigation is the first demonstration of the Science of Behavior Change experimental medicine approach to systematically test and evaluate, in youths, the extent to which an intervention acts on different self-regulation targets. Results suggested that self-regulation targets could be reliably assessed in youths and that delivering home-based interventions focusing on self-regulation skills with youths from low-income families was feasible. Interventions were implemented with high fidelity, and home practice data indicated high intervention dosage. Overall, however, interventions failed to achieve statistical significance. Effect sizes were null to small for executive functioning and approach bias $(.02<d<.19)$ and were null to moderate for emotion regulation and future orientation $(.03<d<.65)$. Results are discussed and synthesized below with regard to implications of findings for assessing self-regulation targets, developing interventions for each target, and the developmental context of self-regulation-focused interventions with youths and youths exposed to poverty.

\section{Assessment of self-regulation targets}

To effectively evaluate interventions that focus on specific self-regulation targets, it is essential to identify measures of self-regulation that are reliable in the population of interest. Testing and validating measures of self-regulation targets in youths is important because measures that are valid in adults might not measure the same processes in youths. Current findings suggest that the measures used in the current study were generally, although not always, reliable in assessing self-regulation targets in youths with a history of living in poverty. The least reliable self-report measures were those requiring youths to reflect on their use of emotion regulation strategies on the CEMS, particularly Worry Coping. Strategies for managing worries may be more subtle and more difficult to identify than strategies for managing anger, especially for youths (Muris, Merckelbach, Meesters, \& van den Brand, 2002). Youths' ability to self-report on worry depends on development of cognitive capacities to con- 
sider multiple outcomes and focus attention on specific elements of a situation or object (Muris et al., 2002). Although the CEMS has been used with youths (Zeman et al., 2001), this study was the first to use the measure with youths living in poverty and as an outcome in an emotion regulation-focused intervention. This is important to note because prior interventions attempting to improve emotion regulation have shown effects on emotion processing skills such as emotion knowledge, or broader social-emotional functioning such as the PATHS (Promoting Alternative Thinking Strategies) program (Domitrovich, Cortes, \& Greenberg, 2007), compared with emotion regulation strategies. It may be important for future measurement work to develop methods that facilitate youths' self-reflection and reporting on nuanced aspects of their own emotion regulation strategies.

Parents reliably reported on child self-regulation; this study confirmed that that these measures performed well in this population. It is important to emphasize that parents remain key informants regarding child functioning at this age. Although youths increasingly experience internal processes to which they alone have access, parents' perspectives remain critical in assessing child selfregulation. Correlation analyses revealed that child- and parent-reported measures of emotion regulation were significantly associated. Significant associations were also observed for observed frustration and child-reported measures of emotion regulation, whereas behavioral tasks assessing approach bias were unrelated to child-reported responses on the Power of Food Scale, suggesting that correlations between methods of assessment varied by self-regulation target. Different assessment methods may yield different findings, as they did here, in part because they could be tapping into different aspects of self-regulation. Yet, each one may add important information. For example, task responses may indicate the ability to maintain attentional focus in a computer context, parent reports may indicate the child's broader functional capacity across contexts, and child self-reports may indicate internal states that are unknown to others.

\section{Intervention development and implementation}

One goal of this study was to determine the feasibility of implementing self-regulation-focused interventions among youths who were living in low-income environments and were at risk for poorer self-regulation as well as poorer health outcomes. We delivered interventions at home to decrease the burden on families (e.g., arranging care for other youths, time and transportation costs). Results suggested that this was a feasible, although intensive, model. Although parents were present, intervention activities were centered on the child. Our bachelor's-level interventionists were able to deliver interventions with high fidelity despite home settings that were often chaotic due to limited space, other youths present, and/or various interruptions. Youths and parents reported engaging in high levels of home practice, and our objective measure (for the executive functioning intervention) indicated that youths played the game in between training sessions. Given the mostly null results and small effect sizes, however, it will be important for future work to weigh the costs of this type of individual, home-based intervention model against other self-regulation-focused intervention models that may be less burdensome on staff and families. For example, either remote delivery approaches or group sessions in community-based settings could be less burdensome than home-based, individual training.

\section{Impact of self-regulation-focused interventions}

\section{Executive functioning}

The impact of executive functioning-focused intervention was not significant. This is consistent with meta-analytic reviews that computer-based working memory trainings have limited effects on cognitive, behavioral, and academic functioning in youths (Melby-Lervåg, Redick, \& Hulme, 2016; Schwaighofer, Fischer, \& Bühner, 2015). That is, whereas explicitly practicing an executive functioning task may improve performance on that task, this benefit might not translate or "transfer" to other executive functioning or related skills. Deliberate executive functioning practice is often devoid of context such that explicit training does not align well with the everyday challenges a child may experience on a regular basis. This is an important translational issue to consider in interventions seeking to use executive functioning as a mechanism of behavior change to promote health behaviors, particularly in youths. Regarding the current sample, it is also important to note that exposure to poverty 
and socioeconomic hardship uniquely predicts child executive functioning performance (Raver et al., 2013). Although the current findings are consistent with some of the recent literature questioning the efficacy of working memory training (e.g., Redick, 2019; Simons et al., 2016), they are inconsistent with literature detailing narrow transfer of executive function training tasks (Jaeggi et al., 2011; Jones et al., 2020), including those supporting that executive function training is equally beneficial (Katz \& Shah, 2017), or even more beneficial, for youths with the most to gain (Blair \& Raver, 2014; Diamond, 2013). It is possible that floor effects were observed on the executive function tasks (digit span and go/no-go), such that youths were performing within normal limits, or that the amount of working memory training completed by participants in the current study was not enough to lead to observable benefits. Therefore, important goals for future work are to determine how to promote executive functioning among youths who have poor baseline self-regulation and to develop interventions that work with youths experiencing high-risk contexts such as poverty.

\section{Emotion regulation}

Using relaxation training to target emotion regulation skills yielded significant reduction in instances of child-reported anger dysregulation. This is consistent with a prior meta-analysis (Takacs \& Kassai, 2019), which concluded that implicit approaches to improving self-regulation, such as mindfulness and biofeedback-mediated interventions for relaxation, are more effective than explicit training tasks. Implicit approaches are more engaging and may generalize to other adaptive functioning skills. Given connections between emotion regulation and health behaviors (Compas \& Boyer, 2001), findings from the current study suggest that biofeedback-mediated emotion regulation training could be an effective tool to enhance emotion regulation among youths living in poverty in order to improve long-term health outcomes.

The strongest effects were observed for measures of dysregulated emotion, with the emotion regulation intervention group endorsing less dysregulated emotions and better emotion coping strategies compared with non-emotion regulation groups. Although no group differences were observed for the frustration task, this is likely attributable to floor effects. Specifically, because the paradigm used to elicit frustration resulted in few observed instances of frustration, there was limited opportunity for change. Another important measurement consideration is method of assessment (e.g., questionnaire based or behavioral) given that intervention effects may vary as a function of measurement type. Emotion regulation outcome measures varied in terms of their focus on "state" versus "trait" aspects of emotion regulation. For example, positive and negative affect as measured by the parent-reported PANAS may reflect temperament traits that are thought to be more stable and less likely to change with intervention (Charles, Reynolds, \& Gatz, 2001). In contrast, although coping strategies as measured on the CEMS may vary, reporting on one's own coping strategies requires complex metacognitive and self-reflection skills (Muris et al., 2002), which may account for inconsistent findings for anger versus worry. The current intervention targeted a specific relaxation technique rather than instruction on strategies to cope with difficult feelings, which may also explain the nonsignificant effects on these coping scales.

\section{Future orientation}

Findings indicated that youths who participated in the EFT intervention used more details to describe future events compared with non-EFT intervention peers. However, this finding did not generalize to other future orientation outcome measures. Although questionnaire-based future orientation measures were reliable, it is possible that these were not an optimal assessment tool for youths of this age. Specifically, the ability to project oneself into the future and envision the future depends on the development of cognitive capacities related to metacognition, self-reflection, and abstraction (Andreoni et al., 2019). Of note, there was a significant age difference of 2 months between youths who received EFT and those who did not, so it is possible that the intervention effect reflects differences in cognitive development that may support future orientation. As youths enter middle childhood, they begin to improve in their ability to hold the future in mind while considering the present. Therefore, future orientation is important for developing the ability to not only imagine longterm outcomes but also link current behaviors to future outcomes, which researchers have identified as essential for promoting healthy behaviors (Daniel et al., 2015; Stein et al., 2016). It is possible that 
the lack of significant findings for other future orientation measures is attributable to limitations of adapting assessments originally developed for adults. Future work should consider developing measures that account for the ongoing future orientation development during this age period.

\section{Approach bias}

The approach bias intervention had no effect on outcomes. This is consistent with a recent metaanalysis finding limited bias modification training effects in youths (Cristea, Mogoașe, David, \& Cuijpers, 2015). Similar to future orientation, the approach bias intervention was initially designed for use with adults and adapted for youths. Even within the adult literature, the approach bias modification literature is inconsistent (Becker, Jostmann, Wiers, \& Holland, 2015). The null effects for approach bias are consistent with smaller pilot studies in youths (Verbeken et al., 2018; Warschburger, Gmeiner, Morawietz, \& Rinck, 2018). The nature of the intervention called youths' attention to images of foods that may be inherently appealing (sweets) while asking them to push those images away. It is possible that drawing attention to the stimuli (even with the goal of increasing avoidance) may increase the salience of the stimuli and therefore not have an impact on approach bias at this age. Our sample of youths who have lived in poverty is an understudied yet important population within this literature (Ferentzi et al., 2018). In addition, reward sensitivity may account for variation in response to approach bias intervention (Somerville, Jones, \& Casey, 2010), especially if some youths are more responsive to food as a reward than others. Most approach bias assessments used food as a stimulus to remain consistent with prior research on approach bias in youths. It will be important for future work to consider possible domain-specific approach biases as well as individual differences in reward sensitivity that could moderate intervention response.

\section{Limitations}

Although this study had many strengths, including an experimental design and random assignment, measurement of fidelity and dose, and use of objective measures and multiple informant methods to assess self-regulation, there were several limitations. The study was conducted in a sample of youths with a history of living in poverty, so despite the importance of understanding how selfregulation interventions work in this population, findings might not be generalizable to other populations. To reduce burden on youths and their families, there were home practice activities only for certain interventions. In line with the goal to develop lighter touch, less burdensome self-regulation interventions, particularly as virtual interactions have taken on new significance with lockdown procedures due to COVID-19, future studies may wish to use an audio recorder to practice episodic future thinking or develop a mobile application for approach bias. Regarding measurement, not all measures of a given construct were correlated, which is often the case in research using multiple methods. We sought to test measures of self-regulation that could be used in other interventions; although many measures were psychometrically sound, some demonstrated low reliability, suggesting that additional measurement work is needed. Namely, the CEMS might not be adequately constructed in a manner that reliably measures youths' reports of coping with worries.

It is also possible that although interventions were designed to address specific self-regulation targets, they may have also acted on other aspects of self-regulation given that these can overlap (Miyake et al., 2000). Post hoc analyses were conducted to address this limitation, and results indicated either no or few significant cross-domain intervention effects, addressing this issue somewhat. Another potential limitation is that because these interventions were adapted from prior work and designed to focus on the individual child, parents were not directly included despite their importance in shaping child self-regulation (of note is that parents consented and were at the home during the interventions). Finally, the sample size of the current study was smaller than anticipated. Therefore, the study had adequate power to detect only medium to large effects of $d=.53$ or larger. For completeness, we reported all effect sizes so that future studies with larger samples can confirm these findings. 


\section{Conclusion}

A novel contribution of this study was using the experimental medicine method to test selfregulation as a potential mechanism of behavior change in youths. Self-regulation targets were identified, and issues with reliability of some of the child-reported scales should be addressed in future research. In terms of attempting to change self-regulation targets, current results do not support undertaking such interventions despite the potential importance that small treatment effects of self-regulation interventions may have over time (O'Carroll, 2020). It is possible that a focus on individual self-regulation skills in an abstract context, as in the current study, may be less effective for improving self-regulation than interventions that account for the context in which children may need self-regulation (Doebel, 2020). For example, youths may need to identify a goal that is important to them and requires self-regulation and practice self-regulation skills in service of that goal (e.g., remembering to take medication for a chronic illness) in order to maximize impact of individually focused interventions (Miller, Lo, Bauer, \& Fredericks, 2020). It will be important to consider the following in future work: (a) whether alternate self-regulation targets are more malleable at this age or whether other measures are more reliable assessments of self-regulation targets for youths from lowincome backgrounds, (b) that interventions seeking to improve self-regulation skills may need to integrate them into contexts where children can apply such skills, and (c) less burdensome approaches that may be important modes of intervention for this population.

\section{Acknowledgement}

This research was supported by the National Institutes of Health (NIH) Science of Behavior Change Common Fund Program through an award administered by the Eunice Kennedy Shriver National Institute of Child Health and Human Development (NICHD UH2HD087979). Sharon L. Lo was supported by T32HD079350 and F32HD100025 from the NICHD. The content of the manuscript is solely the responsibility of the authors and does not necessarily represent the official views of the NICHD.

\section{References}

Addis, D. R., Wong, A. T., \& Schacter, D. L. (2008). Age-related changes in the episodic simulation of future events. Psychological Science, 19, 33-41.

Akshoomoff, N., Beaumont, J. L., Bauer, P. J., Dikmen, S. S., Gershon, R. C., Mungas, D., ... Heaton, R. K. (2013). VIII. NIH Toolbox Cognition Battery (CB): Composite scores of crystallized, fluid, and overall cognition. Monographs of the Society for Research in Child Development, 78, 119-132.

Allan, J. L., McMinn, D., \& Daly, M. (2016). A bidirectional relationship between executive function and health behavior: Evidence, implications, and future directions. Frontiers in Neuroscience, 10. https://doi.org/10.3389/fnins.2016.00386.

Andreoni, J., Kuhn, M. A., List, J. A., Samek, A., Sokal, K., \& Sprenger, C. (2019). Toward an understanding of the development of time preferences: Evidence from field experiments. Journal of Public Economics, 177104039.

Barnett, E., Spruijt-Metz, D., Unger, J. B., Rohrbach, L. A., Sun, P., \& Sussman, S. (2013). Bidirectional associations between future time perspective and substance use among continuation high-school students. Substance Use E Misuse, 48, 574-580.

Becker, D., Jostmann, N. B., Wiers, R. W., \& Holland, R. W. (2015). Approach avoidance training in the eating domain: Testing the effectiveness across three single session studies. Appetite, 85, 58-65.

Bell, C. (2003). The Journey to Wild Divine: The companion guide. Boulder, CO: The Wild Divine Project.

Berg, C. A., Wiebe, D. J., Suchy, Y., Hughes, A. E., Anderson, J. H., Godbey, E. I., ... White, P. C. (2014). Individual differences and day-to-day fluctuations in perceived self-regulation associated with daily adherence in late adolescents with type 1 diabetes. Journal of Pediatric Psychology, 39, 1038-1048.

Berger, R. H., Miller, A. L., Seifer, R., Cares, S. R., \& LeBourgeois, M. K. (2012). Acute sleep restriction effects on emotion responses in 30- to 36-month-old children. Journal of Sleep Research, 21, 235-246.

Berridge, K. C., Ho, C. Y., Richard, J. M., \& DiFeliceantonio, A. G. (2010). The tempted brain eats: Pleasure and desire circuits in obesity and eating disorders. Brain Research, 1350, 43-64.

Best, J. R. (2010). Effects of physical activity on children's executive function: Contributions of experimental research on aerobic exercise. Developmental Review, 30, 331-551.

Bickel, W. K., Quisenberry, A. J., Moody, L., \& Wilson, A. G. (2015). Therapeutic opportunities for self-control repair in addiction and related disorders: Change and the limits of change in trans-disease processes. Clinical Psychological Science, 3, $140-153$.

Blair, C., \& Diamond, A. (2008). Biological processes in prevention and intervention: The promotion of self-regulation as a means of preventing school failure. Development and Psychopathology, 20, 899-911.

Blair, C., Kuzawa, C. W., \& Willoughby, M. T. (2020). The development of executive function in early childhood is inversely related to change in body mass index: Evidence for an energetic tradeoff? Developmental Science, 23 e12860. 
Blair, C., \& Raver, C. C. (2014). Closing the achievement gap through modification of neurocognitive and neuroendocrine function: Results from a cluster randomized controlled trial of an innovative approach to the education of children in kindergarten. PLoS One, 9(11) e112393.

Bromberg, U., Wiehler, A., \& Peters, J. (2015). Episodic future thinking is related to impulsive decision making in healthy adolescents. Child Development, 86, 1458-1468.

Brown, C. S., Mistry, R. S., \& Yip, T. (2019). Moving from the margins to the mainstream: Equity and justice as key considerations for developmental science. Child Development Perspectives, 13, 235-240.

Brown, L. K., Houck, C., Lescano, C., Donenberg, G., Tolou-Shams, M., \& Mello, J. (2012). Affect regulation and HIV risk among youth in therapeutic schools. AIDS Behavior, 16, 2272-2278.

Buske-Kirschbaum, A., Jobst, S., Wustmans, A., Kirschbaum, C., Rauh, W., \& Hellhammer, D. (1997). Attenuated free cortisol response to psychosocial stress in children with atopic dermatitis. Psychosomatic Medicine, 59, 419-426.

Calkins, S. D., Dollar, J. M., \& Wideman, L. (2019). Temperamental vulnerability to emotion dysregulation and risk for mental and physical health challenges. Development and Psychopathology, 31, 957-970.

Cappelleri, J. C., Bushmakin, A. G., Gerber, R. A., Leidy, N. K., Sexton, C. C., Karlsson, J., \& Lowe, M. R. (2009). Evaluating the Power of Food Scale in obese subjects and a general sample of individuals: Development and measurement properties. International Journal of Obesity, 33, 913-922.

Charles, S. T., Reynolds, C. A., \& Gatz, M. (2001). Age-related differences and change in positive and negative affect over 23 years. Journal of Personality and Social Psychology, 80, 136-151.

Collins, L. M., Dziak, J. J., Kugler, K. C., \& Trail, J. B. (2014). Factorial experiments: Efficient tools for evaluation of intervention components. American Journal of Preventive Medicine, 47, 498-504.

Compas, B. E., \& Boyer, M. C. (2001). Coping and attention: Implications for child health and pediatric conditions. Journal of Developmental \& Behavioral Pediatrics, 22, 323-333.

Cristea, I. A., Mogoașe, C., David, D., \& Cuijpers, P. (2015). Practitioner review: Cognitive bias modification for mental health problems in children and adolescents: A meta-analysis. Journal of Child Psychology and Psychiatry, 56, 723-734.

Daniel, T. O., Said, M., Stanton, C. M., \& Epstein, L. H. (2015). Episodic future thinking reduces delay discounting and energy intake in children. Eating Behaviors, 18, 20-24.

DelGiudice, M. (2018). Middle childhood: An evolutionary-developmental synthesis. In N. Halfon, C. B. Forrest, R. M. Lerner, \& E. M. Faustman (Eds.), Handbook of life course health development (pp. 95-107). Cham, Switzerland: Springer.

Diamond, A. (2013). Executive functions. Annual Review of Psychology, 64, 135-168.

Diamond, A., \& Ling, D. S. (2019). Aerobic-exercise and resistance-training interventions have been among the least effective ways to improve executive functions of any method tried thus far. Developmental Cognitive Neuroscience, 37100572.

Dickson, H., Kavanagh, D. J., \& MacLeod, C. (2016). The pulling power of chocolate: Effects of approach-avoidance training on approach bias and consumption. Appetite, 99, 46-51.

Dimick, J. B., \& Ryan, A. M. (2014). Methods for evaluating changes in health care policy: The difference-in-differences approach. JAMA, 312, 2401-2402.

Divine, W. (2006). Relaxing rhythms 15-step guided training program (Version 11.5) [computer program]. Las Vegas, NV: Wild Divine.

Doebel, S. (2020). Rethinking executive function and its development. Perspectives on Psychological Science, 15, 942-956.

Domitrovich, C. E., Cortes, R. C., \& Greenberg, M. T. (2007). Improving young children's social and emotional competence: A randomized trial of the preschool "PATHS" curriculum. Journal of Primary Prevention, 28, 67-91.

Eberl, C., Wiers, R. W., Pawelczack, S., Rinck, M., Becker, E. S., \& Lindenmeyer, J. (2013). Approach bias modification in alcohol dependence: Do clinical effects replicate and for whom does it work best? Developmental Cognitive Neuroscience, 4, 38-51.

Ebesutani, C., Okamura, K., Higa-McMillan, C., \& Chorpita, B. F. (2011). A psychometric analysis of the Positive and Negative Affect Schedule for Children-Parent Version in a school sample. Psychological Assessment, 23, 406-416.

Eisenberg, I. W., Bissett, P. G., Zeynep Enkavi, A., Li, J., MacKinnon, D. P., Marsch, L. A., \& Poldrack, R. A. (2019). Uncovering the structure of self-regulation through data-driven ontology discovery. Nature Communications, 10, 2319.

Ferentzi, H., Scheibner, H., Wiers, R., Becker, E. S., Lindenmeyer, J., Beisel, S., \& Rinck, M. (2018). Retraining of automatic action tendencies in individuals with obesity: A randomized controlled trial. Appetite, 126, 66-72.

Gearhardt, A. N., Miller, A. L., Sturza, J., Epstein, L. H., Kaciroti, N., \& Lumeng, J. C. (2017). Behavioral associations with overweight in low-income children. Obesity, 25, 2123-2127.

Gott, C., \& Lah, S. (2014). Episodic future thinking in children compared to adolescents. Child Neuropsychology, 20, 625-640.

Grammer, J. K., Carrasco, M., Gehring, W. J., \& Morrison, F. J. (2014). Age-related changes in error processing in young children: A school-based investigation. Developmental Cognitive Neuroscience, 9, 93-105.

Greenwald, A. G., Nosek, B. A., \& Banaji, M. R. (2003). Understanding and using the Implicit Association Test: I. An improved scoring algorithm. Journal of Personality and Social Psychology, 85, 197-216.

Groppe, K., \& Elsner, B. (2014). Executive function and food approach behavior in middle childhood. Frontiers in Psychology, 5. https://doi.org/10.3389/fpsyg.2014.00447.

Groppe, K., \& Elsner, B. (2015). The influence of hot and cool executive function on the development of eating styles related to overweight in children. Appetite, 87, 127-136.

Hall, P. A., \& Marteau, T. M. (2014). Executive function in the context of chronic disease prevention: Theory, research and practice. Preventive Medicine, 68, 44-50.

Houben, K., \& Jansen, A. (2015). Chocolate equals stop. Chocolate-specific inhibition training reduces chocolate intake and go associations with chocolate. Appetite, $87,318-323$.

Isasi, C. R., Ostrovsky, N. W., \& Wills, T. A. (2013). The association of emotion regulation with lifestyle behaviors in inner-city adolescents. Eating Behaviors, 14, 518-521.

Jaeggi, S. M., Buschkuehl, M., Jonides, J., \& Shah, P. (2011). Short- and long-term benefits of cognitive training. Proceedings of the National Academy of Sciences of the United States of America, 108, 10081-10086.

Jansen, A., Houben, K., \& Roefs, A. (2015). A cognitive profile of obesity and its translation into new interventions. Frontiers in Psychology, 6. https://doi.org/10.3389/fpsyg.2015.01807. 
Jones, M. R., Katz, B., Buschkuehl, M., Jaeggi, S. M., \& Shah, P. (2020). Exploring N-back cognitive training for children with ADHD. Journal of Attention Disorders, 24, 704-719.

Kakoschke, N., Kemps, E., \& Tiggemann, M. (2017). Approach bias modification training and consumption: A review of the literature. Addictive Behaviors, 64, 21-28.

Kassai, R., Futo, J., Demetrovics, Z., \& Takacs, Z. K. (2019). A meta-analysis of the experimental evidence on the near- and fartransfer effects among children's executive function skills. Psychological Bulletin, 145, 165-188.

Katz, B., Jaeggi, S., Buschkuehl, M., Stegman, A., \& Shah, P. (2014). Differential effect of motivational features on training improvements in school-based cognitive training. Frontiers in Human Neuroscience, 8. https://doi.org/10.3389/ fnhum.2014.00242.

Katz, B., \& Shah, P. (2017). The role of child socioeconomic status in cognitive training outcomes. Journal of Applied Developmental Psychology, 53, 139-150.

Katz, B., Shah, P., \& Meyer, D. E. (2018). How to play 20 questions with nature and lose: Reflections on 100 years of braintraining research. Proceedings of the National Academy of Sciences of the United States of America, 115, 9897-9904.

Kemps, E., Tiggemann, M., Martin, R., \& Elliott, M. (2013). Implicit approach-avoidance associations for craved food cues. Journal of Experimental Psychology: Applied, 19, 30-38.

Khalili Kermani, F., Mohammadi, M. R., Yadegari, F., Haresabadi, F., \& Sadeghi, S. M. (2016). Working memory training in the form of structured games in children with attention deficit hyperactivity disorder. Iran Journal of Psychiatry, 11, $224-233$.

Koffarnus, M. N., \& Bickel, W. K. (2014). A 5-trial adjusting delay discounting task: Accurate discount rates in less than one minute. Experimental and Clinical Psychopharmacology, 22, 222-228.

Kupst, M. J., Butt, Z., Stoney, C. M., Griffith, J. W., Salsman, J. M., Folkman, S., \& Cella, D. (2015). Assessing stress and self-efficacy for the NIH Toolbox for Neurological and Behavioral Function. Anxiety, Stress, and Coping, 28, 531-544.

Lansing, A. H., \& Berg, C. A. (2014). Topical review: Adolescent self-regulation as a foundation for chronic illness selfmanagement. Journal of Pediatric Psychology, 39, 1091-1096.

Lau, J. Y. (2013). Cognitive bias modification of interpretations: A viable treatment for child and adolescent anxiety? Behaviour Research and Therapy, 51, 614-622.

Lehrer, P., Kaur, K., Sharma, A., Shah, K., Huseby, R., Bhavsar, J., \& Zhang, Y. (2020). Heart rate variability biofeedback improves emotional and physical health and performance: A systematic review and meta analysis. Applied Psychophysiology and Biofeedback, 45, 109-129.

Levitan, R. D., \& Davis, C. (2010). Emotions and eating behaviour: Implications for the current obesity epidemic. University of Toronto Quarterly, 79, 783-799.

Liang, J., Matheson, B. E., Kaye, W. H., \& Boutelle, K. N. (2014). Neurocognitive correlates of obesity and obesity-related behaviors in children and adolescents. International Journal of Obesity, 38, 494-506.

Lin, H., \& Epstein, L. H. (2014). Living in the moment: Effects of time perspective and emotional valence of episodic thinking on delay discounting. Behavioral Neuroscience, 128, 12-19.

Lowe, M. R., Butryn, M. L., Didie, E. R., Annunziato, R. A., Thomas, J. G., Crerand, C. E., ... Halford, J. (2009). The Power of Food Scale: A new measure of the psychological influence of the food environment. Appetite, 53, 114-118.

Luis-Ruiz, S., Caldú, X., Sánchez-Castañeda, C., Pueyo, R., Garolera, M., \& Jurado, M. Á. (2020). Is cognitive training an effective tool for improving cognitive function and real-life behaviour in healthy children and adolescents? A systematic review. Neuroscience \& Biobehavioral Reviews, 116, 268-282.

Matheny, A. P., Wachs, T. D., Ludwig, J. L., \& Phillips, K. (1995). Bringing order out of chaos: Psychometric characteristics of the Confusion, Hubbub, and Order Scale. Journal of Applied Developmental Psychology, 16, 429-444.

McCabe, K., \& Barnett, D. (2000). The relation between familial factors and the future orientation of urban, African American sixth graders. Journal of Child and Family Studies, 9, 491-508.

Melby-Lervåg, M., Redick, T. S., \& Hulme, C. (2016). Working memory training does not improve performance on measures of intelligence or other measures of "far transfer" evidence from a meta-analytic review. Perspectives on Psychological Science, $11,512-534$.

Miller, A. L., Gearhardt, A. N., Fredericks, E. M., Katz, B., Shapiro, L. F., Holden, K., ... Lumeng, J. C. (2018). Targeting self-regulation to promote health behaviors in children. Behaviour Research and Therapy, 101, 71-81.

Miller, A. L., Lo, S. L., Bauer, K. W., \& Fredericks, E. M. (2020). Developmentally informed behaviour change techniques to enhance self-regulation in a health promotion context: A conceptual review. Health Psychology Review, 14, 116-131.

Miller, R. B., \& Brickman, S. J. (2004). A model of future-oriented motivation and self-regulation. Educational Psychology Review, 16, 9-33.

Mischel, W., Shoda, Y., \& Rodriguez, M. I. (1989). Delay of gratification in children. Science, 244, 933-938.

Miyake, A., Friedman, N. P., Emerson, M. J., Witzki, A. H., Howerter, A., \& Wager, T. D. (2000). The unity and diversity of executive functions and their contributions to complex "frontal lobe" tasks: A latent variable analysis. Cognitive Psychology, 41, 49-100.

Muris, P., Merckelbach, H., Meesters, C., \& van den Brand, K. (2002). Cognitive development and worry in normal children. Cognitive Therapy and Research, 26, 775-787.

Nielsen, L., Riddle, M., King, J. W., Aklin, W. M., Chen, W., Clark, D., ... Ferrer, R. (2018). The NIH Science of Behavior Change program: Transforming the science through a focus on mechanisms of change. Behaviour Research and Therapy, 101, 3-11.

Nigg, J. T. (2017). Annual research review: On the relations among self-regulation, self-control, executive functioning, effortful control, cognitive control, impulsivity, risk-taking, and inhibition for developmental psychopathology. Journal of Child Psychology and Psychiatry, 58, 361-383.

Nurmi, J.-E. (2005). Thinking about and acting upon the future: Development of future orientation across the life span. In A. S. J. Joireman (Ed.), Understanding behavior in the context of time: Theory, research, and application (pp. 31-57). Mahwah, NJ: Lawrence Erlbaum.

O'Carroll, R. E. (2020). Self-regulation interventions-What do we know and where should we go? Health Psychology Review, 14, 159-164. 
Oyserman, D., Brickman, D., \& Rhodes, M. (2007). School success, possible selves, and parent school involvement. Family Relations, 56, 479-489.

Patrick, M. E., Blair, C., \& Maggs, J. L. (2008). Executive function, approach sensitivity, and emotional decision making as influences on risk behaviors in young adults. Journal of Clinical and Experimental Neuropsychology, 30, 449-462.

Prabhakar, J., \& Hudson, J. A. (2014). The development of future thinking: Young children's ability to construct event sequences to achieve future goals. Journal of Experimental Child Psychology, 127, 95-109.

Radloff, L. (1977). The CES-D Scale: A self-report depression scale for research in the general population. Applied Psychological Measurement, 1, 385-401.

Raver, C. C., Blair, C., \& Willoughby, M. (2013). Poverty as a predictor of 4-year-olds' executive function: New perspectives on models of differential susceptibility. Developmental Psychology, 49, 292-304.

Raynor, H. A., \& Epstein, L. H. (2003). The relative-reinforcing value of food under differing levels of food deprivation and restriction. Appetite, 40, 15-24.

Redick, T. S. (2019). The hype cycle of working memory training. Current Directions in Psychological Science, 28, 423-429.

Reimann, Z., Miller, J. R., Dahle, K. M., Hooper, A. P., Young, A. M., Goates, M. C., ... Crandall, A. (2020). Executive functions and health behaviors associated with the leading causes of death in the United States: A systematic review. Journal of Health Psychology, 25, 186-196.

Riggs, N. R., Spruijt-Metz, D., Chou, C.-P., \& Pentz, M. A. (2011). Relationships between executive cognitive function and lifetime substance use and obesity-related behaviors in fourth grade youth. Child Neuropsychology, 18, 1-11.

Robson, D. A., Allen, M. S., \& Howard, S. J. (2020). Self-regulation in childhood as a predictor of future outcomes: A meta-analytic review. Psychological Bulletin, 146, 324-354.

Sawilowsky, S. S. (2009). New effect size rules of thumb. Journal of Modern Applied Statistical Methods, 8, 597-599.

Schwaighofer, M., Fischer, F., \& Bühner, M. (2015). Does working memory training transfer? A meta-analysis including training conditions as moderators. Educational Psychologist, 50, 138-166.

Shockey, D. P., Menzies, V., Glick, D. F., Taylor, A. G., Boitnott, A., \& Rovnyak, V. (2013). Preprocedural distress in children with cancer: An intervention using biofeedback and relaxation. Journal of Pediatric Oncology Nursing, 30, 129-138.

Simons, D. J., Boot, W. R., Charness, N., Gathercole, S. E., Chabris, C. F., Hambrick, D. Z., \& Stine-Morrow, E. A. (2016). Do “braintraining" programs work? Psychological Science in the Public Interest, 17, 103-186.

Sleddens, E. F., Kremers, S. P., De Vries, N. K., \& Thijs, C. (2013). Measuring child temperament: Validation of a 3-item temperament measure and 13-item impulsivity scale. European Journal of Developmental Psychology, 10, $392-401$.

Somerville, L. H., Jones, R. M., \& Casey, B. (2010). A time of change: Behavioral and neural correlates of adolescent sensitivity to appetitive and aversive environmental cues. Brain and Cognition, 72, 124-133.

Stein, J. S., Wilson, A. G., Koffarnus, M. N., Daniel, T. O., Epstein, L. H., \& Bickel, W. K. (2016). Unstuck in time: Episodic future thinking reduces delay discounting and cigarette smoking. Psychopharmacology, 233, 3771-3778.

Sun, X., Li, Y., Cai, L., \& Wang, Y. (2021). Effects of physical activity interventions on cognitive performance of overweight or obese children and adolescents: A systematic review and meta-analysis. Pediatric Research, 89, 46-53.

Takacs, Z. K., \& Kassai, R. (2019). The efficacy of different interventions to foster children's executive function skills: A series of meta-analyses. Psychological Bulletin, 145, 653-697.

Turton, R., Chami, R., \& Treasure, J. (2017). Emotional eating, binge eating and animal models of binge-type eating disorders. Current Obesity Reports, 6, 217-228.

U.S. Bureau of the Census (2018). Poverty thresholds. Washington, DC: Government Printing Office.

Vaske, J. J., Beaman, J., \& Sponarski, C. C. (2017). Rethinking internal consistency in Cronbach's alpha. Leisure Sciences, 39, $163-173$.

Verbeken, S., Boendermaker, W. J., Loeys, T., Moens, E., Goossens, L., Latomme, J., \& Braet, C. (2018). Feasibility and effectiveness of adding an approach avoidance training with game elements to a residential childhood obesity treatment-A pilot study. Behaviour Change, 35, 91-107.

Verbeken, S., Braet, C., Goossens, L., \& van der Oord, S. (2013). Executive function training with game elements for obese children: A novel treatment to enhance self-regulatory abilities for weight-control. Behaviour Research and Therapy, 51, $290-299$.

Vloemans, A. F., Eilander, M. M. A., Rotteveel, J., Bakker-van Waarde, W. M., Houdijk, E., Nuboer, R., ... De Wit, M. (2019). Youth with type 1 diabetes taking responsibility for self-management: The importance of executive functioning in achieving glycemic control: Results from the longitudinal DINO study. Diabetes Care, 42, 225-231.

Wang, Z., Zhou, R., \& Shah, P. (2014). Spaced cognitive training promotes training transfer. Frontiers in Human Neuroscience, 8. https://doi.org/10.3389/fnhum.2014.00217.

Warschburger, P., Gmeiner, M., Morawietz, M., \& Rinck, M. (2018). Battle of plates: A pilot study of an approach-avoidance training for overweight children and adolescents. Public Health Nutrition, 21, 426-434.

Wass, S. V. (2014). Applying cognitive training to target executive functions during early development. Child Neuropsychology, $21,150-166$.

Wechsler, D. (2003). Wechsler Intelligence Scale for Children-WISC-IV. San Antonio, TX: Psychological Corporation.

Weiss, N. H., Sullivan, T. P., \& Tull, M. T. (2015). Explicating the role of emotion dysregulation in risky behaviors: A review and synthesis of the literature with directions for future research and clinical practice. Current Opinion in Psychology, 3, 22-29.

Wiers, C. E., Stelzel, C., Gladwin, T. E., Park, S. Q., Pawelczack, S., Gawron, C. K., ... Bermpohl, F. (2015). Effects of cognitive bias modification training on neural alcohol cue reactivity in alcohol dependence. American Journal of Psychiatry, 172, $335-343$.

Wiers, R. W., Bartholow, B. D., van den Wildenberg, E., Thush, C., Engels, R. C., Sher, K. J., ... Stacy, A. W. (2007). Automatic and controlled processes and the development of addictive behaviors in adolescents: A review and a model. Pharmacology Biochemistry and Behavior, 86, 263-283.

Wills, T. A., Sandy, J. M., \& Yaeger, A. M. (2001). Time perspective and early-onset substance use: A model based on stress-coping theory. Psychology of Addictive Behaviors, 15, 118-125. 
Wyman, P. A., Cross, W., Brown, C. H., Yu, Q., Tu, X., \& Eberly, S. (2010). Intervention to strengthen emotional self-regulation in children with emerging mental health problems: Proximal impact on school behavior. Journal of Abnormal Child Psychology, 38, 707-720.

Zeman, J., Shipman, K., \& Penza-Clyve, S. (2001). Development and initial validation of the Children's Sadness Management Scale. Journal of Nonverbal Behavior, 25, 187-205.

Zimbardo, P. G., \& Boyd, J. N. (2015). Putting time in perspective: A valid, reliable individual-differences metric. In M. Stolarski, N. Fieulaine, \& W. van Beek (Eds.), Time perspective theory; Review, research and application (pp. 17-55). New York: Springer. 